\title{
Trazado visual y limitaciones de la política urbana a finales del Antiguo Régimen. Un caso de Salamanca
}

\author{
José Ramón Nieto González y M. ${ }^{a}$ Nieves Rupérez Almajano *
}

\section{RESUMEN ABSTRACT}

En este estudio se abordan diferentes problemas que obstaculizan la aplicación de una política urbana coherente a finales

del siglo XVIII, como la persistencia de una diversidad jurisdiccional o la existencia de grupos diferenciados entre los profesionales de la construcción, tanto por su formación como por su vinculación a un

promotor, que menoscaban su

imparcialidad. Asimismo se muestra la dificultad de compaginar los principios ilustrados de regularidad y simetría con la práctica de la proyección de las visuales, usual en el Barroco. Se pone también de manifiesto la ineficacia transformadora del criterio de alineación sobre el trazado viario mientras no se amplíen las dimensiones de su aplicación, y la debilidad de la normativa urbana vigente frente al peso de los intereses particulares.
This study approaches the different problems that hindered the application of a coherent urban policy at the end of the 18th century, such as the persistence of jurisdictional diversity or the existence of differentiated groups within the building profession, both due to their training and to their connections with a given developer, which diminished their impartiality. There likewise existed the difficulty of combining the enlightened principles of regularity and symmetry with the practice of the projection of the lines of vision, which was commonplace in the Baroque era. Also revealed is the inefficacy of the criterion of alignment for changing the street layout without broadening the dimensions of its application, as well as the weakness of the prevailing urban norms in the face of private interests.

Si bien podemos constatar interesantes realizaciones urbanísticas durante el Barroco, resulta más difícil encontrar una auténtica política urbana, tal como hoy se entiende. La más mínima alteración en el trazado viario puede llegar a convertirse, en algunos casos, en una compleja cuestión

* Departamento de Historia del Arte y Bellas Artes. Universidad de Salamanca. 
social, merced a la diversidad jurisdiccional existente, a la ausencia de una distribución y definición de las competencias de las respectivas instituciones, a la imprecisión y debilidad de la escasa normativa vigente, e incluso al clientelismo y la formación de los profesionales de la construcción.

Estos conflictos ponen también de manifiesto lo difícil que resulta compaginar el criterio básico que rige buena parte de las intervenciones urbanas en el barroco: la proyección de las visuales ', con el principio de regularidad y linealidad que aconsejaban los teóricos y políticos ilustrados, cuya aplicación implica necesariamente una modificación de las visuales tradicionales cuando se realiza en contextos estructurados históricamente, como son los de la mayoría de las ciudades españolas. En un caso la ordenación urbana está concebida en función del individuo, de ahí que tan importante como la visibilidad, sea el respeto de la luz, la ventilación y, sobre todo, la intimidad de aquel con respecto a sus vecinos, en otro se atiende más a la conveniencia de la colectividad y el "ornato público», pero en el siglo XVIII esta práctica encuentra todavía muchos obstáculos para imponerse.

Un pleito suscitado en Salamanca durante la segunda mitad del siglo XVIII resulta sumamente ilustrativo a este respecto ${ }^{2}$. Pone de relieve las múltiples implicaciones e intereses que pueden llegar a estar en juego en una cuestión urbanística aparentemente tan simple como la modificación de una fachada.

El punto de partida del litigio es la decisión de D. Félix de los Arcos y Encina de reedificar su casa. Con este motivo en junio de 1765 solicitó al Ayuntamiento que le cediese once pies de la calle pública que necesitaba para sacarla hasta la esquina de la casa inmediata perteneciente al marqués de Coquilla, con el fin de lograr la línea recta «tan recomendada en el arte de arquitectura». Tal como era costumbre en estos casos, pasaron a reconocer la casa dos regidores y el carpintero de la Ciudad, José de Coca, que valoraron positivamente la concesión del terreno, puesto que la

BONET CORREA puso ya de manifiesto la importancia de este criterio en el urbanismo barroco, frente a los esquemas geométricos y racionales del Renacimiento o del Neoclasicismo. BONET CORREA, Antonio, «El urbanismo barroco y la plaza del Obradoiro en Santiago de Compostela», en Morfología y ciudad. Barcelona, Gustavo Gili, 1978, págs. 96-99. En Salamanca tenemos constancia de varios casos que atestiguan la plena aplicación de este criterio, que suele plasmarse en planos donde se constatan los trazados visuales. Rupérez Almajano, Mª Nieves, Urbanismo de Salamanca en el siglo XVIII. Salamanca, Delegación en Salamanca del Colegio de Arquitectos de León, 1992, págs. 272 y ss.

2 La mayor parte de la documentación que utilizamos es un largo pleito que se conserva en la Chancillería de Valladolid (A. Ch.V.), Sección Pleitos Civiles, "Moreno", C-3337-3. La documentación municipal y los protocolos notariales de Salamanca completan la información y nos proporcionan la resolución a la que se llegó tras el segundo y definitivo pleito. 
calle superaba los treinta pies de anchura - unos ocho metros y medio-, más que suficientes para la vuelta de los coches, y podía quedar considerablemente mejorada con la eliminación del viejo soportal que tenía y la colocación de un balcón de hierro sobre el pórtico de tres arcos que ahora se proyectaba ${ }^{3}$.

La casa de la polémica estaba ubicada en la calle Zamora, justo al final de la línea que constituía el frente oriental de la plaza de Santo Tomé, en uno de los puntos más céntricos y principales de la ciudad. Estaba flanqueada en el sur por una casa bastante retranqueada del catedrático de medicina don Antonio Cuesta y en su parte norte hacía esquina con una estrecha calle que se dirigía a la parroquia de San Boal; al otro lado de la misma se levantaba un enorme palacio del marqués de Coquilla correspondiente al mayorazgo de los Monroy, cuyo frente formaba una amplio ángulo obtuso, y a sus espaldas quedaban las posesiones de la marquesa de Almarza, que se extendían formando todo el frente de la plaza de San Boal. A juzgar por los informes de los peritos el origen de todas estas edificaciones se podía remontar a finales del siglo XV o comienzos del XVI, y sus fachadas presentaban tanta irregularidad como el trazado de la calle, que en nada había mejorado con los años. Como afirma el arquitecto real don Francisco Moradillo, poco había en Salamanca del «orden y uniformidad que pide el ornato y policía de las ciudades" y "menos en la calle que desde la Plaza, pasando por el combento de Trinitarios Calzado dirige a la de Zamora, pues asta la capillita del Carmen, toda aquella línea está llena de codillos o esconzes, que estrechando la calle cortan las visuales asta la puerta de Zamora» ${ }^{4}$.

La fachada del palacio del marqués de Coquilla, aunque reedificada a comienzos del siglo XVIII, tampoco había respetado la rectitud y parte de la misma se introducía varios pies hacia la calle. Tal como afirman los peritos, y confirman los escasos documentos gráficos que de la vivienda han llegado hasta nosotros, la alteración de los artesonados de las salas principales atestiguaba esta moderna reforma, así como la perfecta cantería de la pared exterior, los balcones de las piezas altas o la interrupción de la

3 Archivo Municipal de Salamanca (A.M.S.), Libro consistorial (L.C.) 1765, fol. 101r. y v. A.Ch.V., exp. cit. ff. 54r.-55v. D. Félix de los Arcos Encina pertenecía al grupo intermedio de propietarios del Antiguo Régimen. Era cadete de las tropas de S.M. cuando se inició el Catastro de Ensenada y poseedor de dos vínculos que a la altura de 1770 le proporcionaban en concepto de rentas, foros y censos unos ingresos próximos a los 5.000 reales de vellón anuales. ZAONERO, Joaquín, Libro de Noticias de Salamanca. Edición crítica de Ricardo. Robledo, Salamanca, Librería Cervantes, 1998, pág. XVIII.

${ }^{4}$ A.Ch. V., exp. cit., fol. 94 r. y v. 
moldura que separaba los pisos superiores, si bien su estructura interna había permanecido intacta ${ }^{5}$. Aparte de los balcones, la única decoración de la fachada eran cuatro escudos que denotaban los rancios linajes de su propietario ${ }^{6}$ (Fig. 1). El palacio tenía una puerta principal hacia la calle Zamora y otra igual junto a la iglesia de San Boal, entre las que mediaban las cocheras y un patio con dos corredores (Figs. 2 y 3). Estos presentaban una estructura adintelada, sostenida en la parte inferior por medio de columnas cuyos capiteles se decoraban con adornos vegetales de indudable progenie gótica, pertenecientes al paso del siglo XV al XVI, momento al que corresponden otros escudos. Más moderna era la escalera principal, cubierta con artesonado morisco, que desembarcaba en una de las galerías; a juzgar por las fotografías conservadas debía tener dos tiros, y si bien mantenía algunos pilares con pináculos y escudo del XVI, su pretil estaba resuelto con balaustres barrocos, fruto de reformas posteriores (Fig. 4).

Parece que fue también con ocasión de las reparaciones realizadas a principios del siglo XVIII, cuando se abrió una ventana grande en el ángulo meridional y más saliente del edificio ${ }^{7}$, correspondiente al despacho, desde la que podía contemplarse sin ningún obstáculo la calle de la Trinidad (primer tramo de la calle Zamora) hasta la entrada de la Plaza Mayor, la calle Concejo, la ermita del Carmen - edificada en 1743 en la bifurcación de ambas - , una parte de plaza de Santo Tomé con su fuente y la p!ıerta de los carros del convento de los Carmelitas descalzos. La privación de estas vistas, con lo que suponían de entretenimiento y diversión, más valiosas incluso que la reducción de la luz y la ventilación de esa ventana, fueron motivos más que suficientes para que, un año des-

\footnotetext{
5 La parte reedificada entre 1701 y 1703 comprendió todo el alto de la fachada - 50 pies - y gran parte del largo - 116 pies - es decir, prácticamente todo el tramo que rompía la rectitud; además se levantaron de nuevo diferentes tabiques interiores, que por la pobreza del material estaban desplomados. Ejecutaron las obras Domingo Díez y Juan Domínguez, y según el reconocimiento posterior de fray Pedro de la Visitación y Francisco de Rivera tuvieron que componer los artesonados que habían quedado destruidos con los derribos, lo que coincide con la declaración de Simón Gabilán realizada en 1766 . Como gran parte de las casas nobiliarias, poseía oratorio. La escalera partía de un tránsito y sobre él se abría una ventana observatorio. El edificio se conservó hasta mediados de este siglo, y en las fotografías se aprecia perfectamente el quiebro que hace la fachada. Archivo Histórico Provincial de Salamanca (A.H.P.S.), Protocolo (Prot.), 4785, ff. 339r.-342r.; Prot. 4786, fol. 297r. y v. Prot. 4787, ff. 422r-423v. A.Ch.V., exp. cit. ff. 13v.-14r.: declaración de Simón Gabilan. Aprálz, Ángel, La casa y la vida en la antigua Salamanca. Salamanca, 1917, pág. 29.

${ }_{6}$ Corresponden a los apellidos Rodríguez de Villafuerte, Monroy, Monroy-Rodríguez de Villafuerte y Águila-Rodríguez de Ledesma. Vid. ÁlvarEz VILLAR, Julián, De Heráldica Salmantina. Historia de la ciudad en el arte de sus blasones. Salamanca, 1997, págs. 97-102. Aprovechamos para agradecerle el material fotográfico que nos ha proporcionado.

Así nos lo hace pensar el hecho de que en la parte reedificada de la fachada, a partir del quiebro, sólo había cinco ventanas que con la situada a la vuelta son las seis de las que se habla en la escritura.
} 


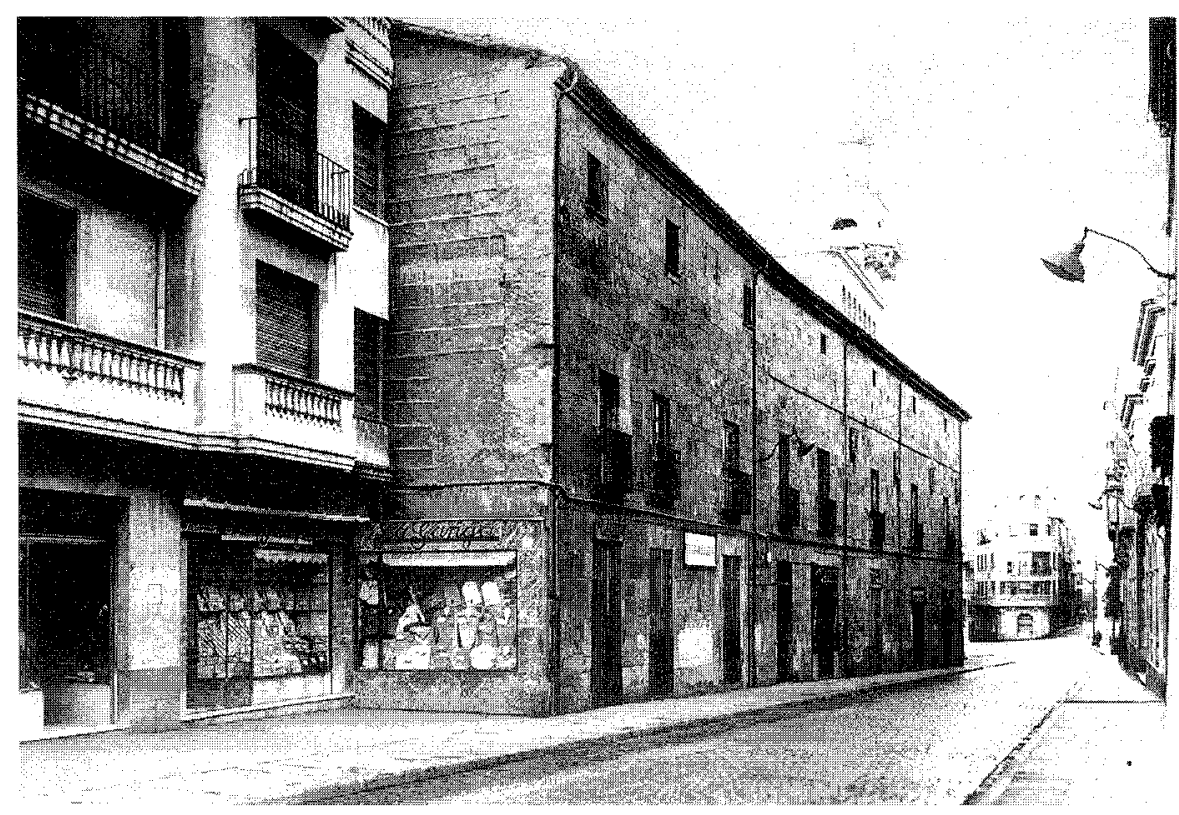

Fig. 1. Fachada de la casa del marqués de Coquilla hacia 1950.

pués, el marqués de Coquilla tratase de impedir la reedificación de la casa de D. Félix de los Arcos en cuanto advirtió las consecuencias que su prolongación sobre la calle podían acarrear sobre su propio palacio.

Para dar una apariencia más objetiva al móvil de su denuncia, el marqués la apoyó con otros dos argumentos. Por una parte, la nueva construcción estrecharía aún más la calle que iba a San Boal, de forma que tanto sus coches como los de la marquesa de Almarza no podrían salir y entrar con la libertad de antes y rozarian su fábrica al pasar; por otra, el viejo soportal, cerrado en una de sus partes, que tenía la casa de don Félix de los Arcos, debía también demolerse por ser una obra muy posterior y «arrimadiza» a su primitiva fábrica, que además del perjuicio que ocasionaba a su palacio, causaba gran fealdad al romper la rectitud de la pared que formaban las posesiones de don Antonio Cuesta y de la señora Dupuy ${ }^{8}$. Esto fue fundamentalmente lo que pidió y estas fueron las razones alegadas.

* A.Ch.V., exp. cit. Exposición de la denuncia, ff. 3r.-4r. El marqués de Coquilla ofrece información sobre estos puntos el 2 de agosto de 1766, ff. $37 \mathrm{r} .39 \mathrm{r}$. y se recibe en 7 de agosto, ff. 58r. 64v. 
Lo sorprendente del caso es que el marqués de Coquilla, D. Vicente Pascual Vázquez Coronado, en realidad vecino y residente en Valencia, no acudió al corregidor o al Municipio de Salamanca, es decir, a la justicia real ordinaria, para resolver el litigio, como habría sido lo lógico tratándose de una cuestión urbanística o de policía regulada, en principio, por las ordenanzas de cada Ciudad, sino que amparándose en su condición de conservador honorario del Estudio ${ }^{9}$, en junio de 1766 presentó la denuncia de nueva obra ante el tribunal escolástico, en el que se seguirá el pleito. Más curioso todavía es el acatamiento de esta vía por parte de D. Félix de los Arcos, ajeno como era a ese fuero ${ }^{10}$, y la completa inhibición del Ayuntamiento en un caso en el que se cuestiona directamente uno de sus acuerdos y su propiedad exclusiva sobre el suelo público.

Precisamente fue este uno de los puntos básicos en los que apoyó su defensa D. Félix de los Arcos: el derecho del Municipio a ceder terreno de las calles si lo consideraba oportuno "para fabricar casas siguiendo la línea recta o para cerrar esconces", práctica tan antigua como ordinaria que avalaban concesiones similares realizadas en 1756 y en mismo año de $1766^{11}$. Esas circunstancias concurrían ahora pues siguiendo el trazado de la calle de Zamora su casa formaría perfecta línea con la del marqués de Coquilla, sin que pudiera perjudicar a ésta en sus luces y aires por mediar entre ambas una calle "bastante ancha y espaciosa", y al mismo tiempo se salvaría la deformidad que había causado el propio palacio del marqués al romper la rectitud que formaba su antigua fachada con los postes del soportal que tenía la suya ${ }^{12}$.

En segundo lugar D. Félix de los Arcos alegará en su favor la sentencia definitiva lograda por Fernán Pérez de Grado —fundador de uno de sus

9 Exhibe certificación de esto. A.Ch.V., exp. cit., fol. 1.

10 En poder posterior a su procurador señala que aunque lo "resistió, por no ser escolástico su juez, le fue forzoso contextar allí el juicio". A.Ch.V., exp. cit., fol. 6. Dejando al margen la falta de competencia de este tribunal para los asuntos de Policía, se anula también la regla que obligaba al actor a seguir el fuero del reo. Sobre este tema, Alonso MoRENo, M. ${ }^{a}$ PAZ, Universidad y sociedad corporativa. Historia del privilegio jurisdiccional del Estudio salmantino. Madrid, Tecnos, 1997, págs. $233,241,267$.

Se presenta certificación al respecto de los terrenos cedidos por el Ayuntamiento a la cofradía de Santa Elena o a la hermandad de ánimas de San Pablo en el arrabal de curtidores, a José de Fontela y a Juan Antonio Hernández en el arrabal del Puente, de varios pies al marqués de Santo Floro para sacar una casa en la calle del Horno y de varias concesiones a la orden tercera de San Francisco. A.CH.V., ex. cit., ff. 49v. 51v. y fol. 54r. Hay constancia notarial de varias de estas cesiones, si bien la parte del marqués no las reconoce. A.H.P.S., Prot. 5196, ff. 118-121, 133r.-136r., 164r.-166r. y 190r.-193r. A.M.S., L.C. de 1766, ff. 182r.-183. Sobre estas ventas también RuPÉREZ AlmAJANO, ob. cit., pág. 133 y 135.

12 Información ofrecida sobre estos puntos por D. Félix de los Arcos y Encina, A.CH.V., ex. cit., 5 de agosto de 1766, ff. 40r. y v. y 65 r. -7 r. 


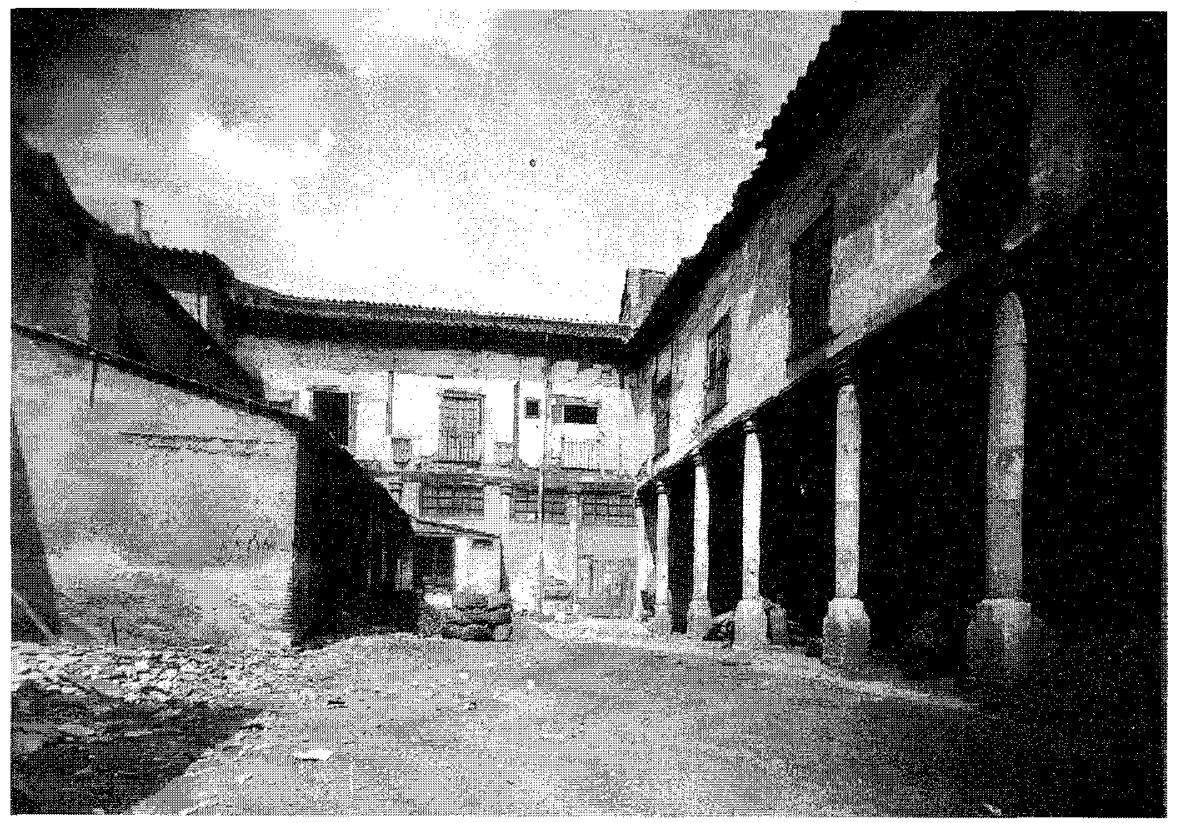

Fig. 2. Vista del patio interior de la casa del marqués de Coquilla.

vínculos - en 1506 para la permanencia de este soportal, cuando el resto de los que había en la línea fueron derribados por orden judicial. La sentencia fue esgrimida de nuevo en 1617 por doña Elena Guillén cuando tanto el procurador general de la Ciudad como don Gonzalo Rodríguez de Monroy intentaron detener la reparación del mismo que se estaba cayendo, pues según su parecer la ley que alegaban para impedirlo «trataba de balcones y salidizos y en este caso no había lugar por ser edificio desde los zimientos" ${ }^{13}$. Ahora la cuestión principal no era defender la permanencia del soportal, cuya deformidad era evidente, sino la propiedad del terreno que ocupaba y la necesidad de incorporar unos pies más del suelo público para mejorar la calle, puesto que la renuncia a la posesión es algo impensable.

13 Según el parecer de esos detractores el soportal favorecía la protección de «gente de mal vivir", que se recogían en él "y salían a capear y hacer otros delitos a los que pasaban", y contravenía la ley 8, del título 7 del libro séptimo de la nueva recopilación (de 1530) que prohibía a cualquier persona labrar ni reedificar saledizo ni soportal después de una vez hecho. No obstante la parte del marqués señala que en esta ocasión los autos quedaron en suspenso. Certificaciones de todo ello, A.CH.V., exp. cit. ff. $44-48$ y 53. 
Como vemos, la posición de uno y otro no puede ser más opuesta y, sin embargo, ambos utilizan el principio de la línea recta en apoyo de sus propuestas, lo que nos permite constatar el significado real de este criterio tan en boga en el siglo XVIII ${ }^{14}$ y su ineficacia transformadora sobre el trazado viario mientras no se amplíen las dimensiones de su aplicación, como queda patente en los planos elaborados por los arquitectos ${ }^{15}$. Sus informes manifiestan también la debilidad de la normativa urbana existente frente al peso de los intereses particulares.

Estos planos e informes constituyen un elemento esencial en el pleito, pues la sentencia final debía basarse en las pruebas de los peritos (Figs. 5 y 6). De hecho lo primero que hizo D. Félix de los Arcos al conocer la denuncia, fue pedir que se hiciese una "vista ocular" y reconocimiento de la obra por expertos en «el arte de architecttura», nombrados por ambas partes, y un tercero en caso de discordia, como solía realizarse en casos similares. El designó a don José Antonio Otero ${ }^{16}$, a quien califica como «inteligente y notoriamente imparcial», mientras el marqués de Coquilla eligió a Simón Gabilán Tomé, que por entonces estaba trabajando en la capilla de la Universidad ${ }^{17}$.

La vista se realizó a las 7 de la mañana del 16 de junio de 1766 -cinco días después de la denuncia-, con asistencia de ambos maestros, don Félix de los Arcos, don Manuel García de la Cruz, administrador y representante del marqués de Coquilla, el juez escolástico y un notario. Una vez leída la denuncia y después del juramento de imparcialidad, los arquitectos procedieron al reconocimiento: «hizieron expeculación de la obra y casa donde se intenta hazer, entraron en la inmediata del denunciante, y después tiraron varias líneas así en las frentes de ellas como en la calle, e hizieron otras dilixencias que les parezió conveniente", hasta considerar que tenían los datos para elaborar el plan y realizar sus declaraciones. Si bien coinciden plenamente en el diseño, difieren completamente en el dictamen e interpretación ${ }^{18}$.

14 Chueca Goltia, Fernando, Breve historia del urbanismo. Madrid, Alianza, 1968, págs. 144146. Para el caso de Salamanca, Rupérez Almajano, ob. cit. págs. 110 y ss.

15 A.CH.V., planos y dibujos C. 36-537 y C-36-538. El primero está firmado por Gabilán y Otero, y el segundo, que viene a ser un detalle del primero, por Gerónimo García de Quiñones.

${ }_{16}$ Era uno de los cinco maestros arquitectos que figuran en el Catastro de la Ensenada, cuñado de Andrés García de Quiñones, que por estas fechas no se encontraba en Salamanca (RoDRíGuEZ, G. DE Ceballos, Alfonso, "Noticias sobre el arquitecto Andrés García de Quiñones", en Archivo Español de Arte, núm. 161 (1968), págs. 35 y ss.). En septiembre de 1766 Otero estaba ocupado en las obras del fuerte de la Concepción de Aidea del Obispo, próximo a la frontera portuguesa.

17 En su informe se califica de arquitecto «mayor que fue de la Santa Yglesia de León, aparejador de obras reales y actual director de la real Capilla de esta Universidad». Sobre este personaje, Rodriguez G. de Ceballos, Alfonso, y Nieto González, José Ramón, «Aportaciones a Simón Gabilán Tomém, en Archivo Español de Arte, núm. 213, 1981, págs. 29-60.

${ }_{18}$ A.CH.V., exp. cit., ff. 7r.-9v. 


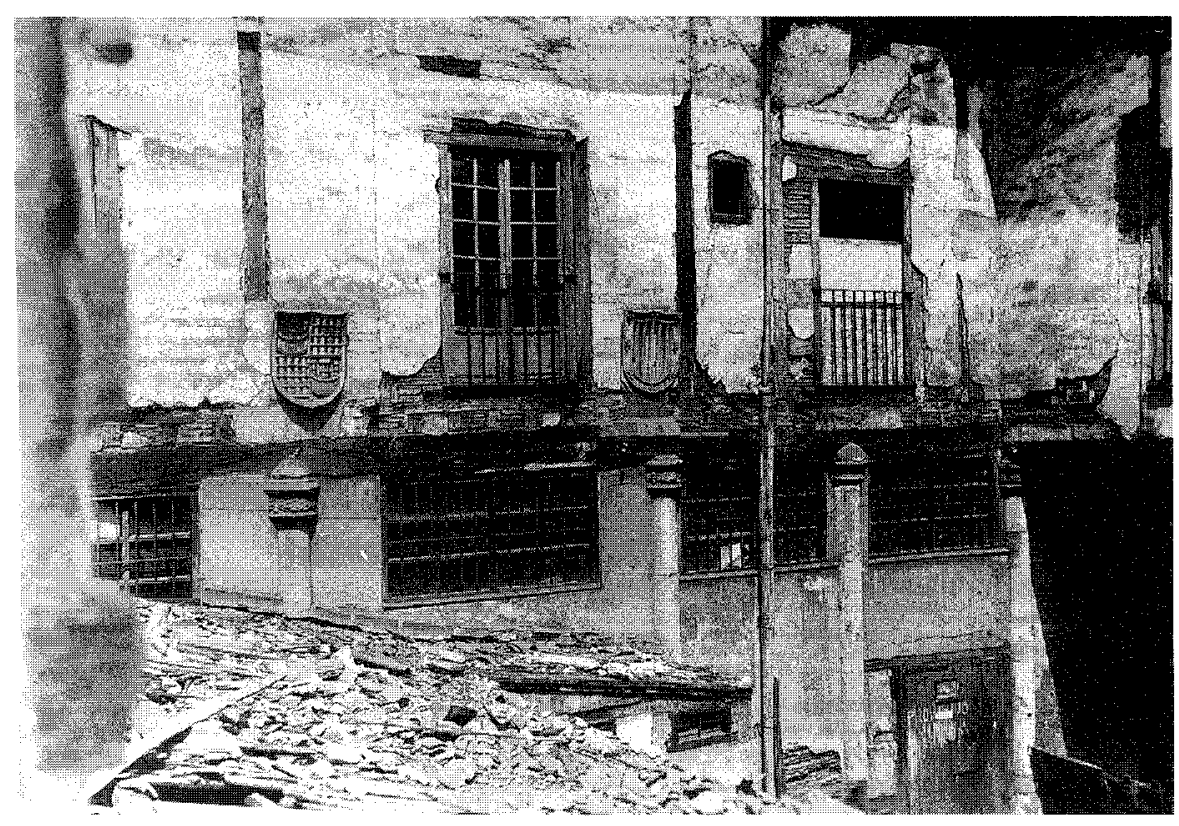

Fig. 3. Detalle de una de las crujias del patio.

Ambos apoyan sus informes fundamentalmente en las Ordenanzas de Torija y de Ardemans, puesto que Salamanca no disponía de una regulación específica para las cuestiones urbanísticas o de policía. José de Otero, sin embargo, no deja de recordar la libertad que el propio derecho concedía a los peritos para resolver lo más conveniente en cada situación, dado que esas normas, si bien útiles y orientativas, no llegaban a contemplar toda la casuística que podía originarse en una ciudad. Desde luego su insuficiencia queda patente desde el momento en que permitían defender posturas contradictorias o incompatibles ${ }^{19}$.

Así Otero no encuentra razón alguna para oponerse a la obra proyectada pues tanto el capítulo treinta de Torija como el primero de las Ordenanzas de Ardemans recomiendan explícitamente que las fachadas que forman las calles guarden una misma «tirantez», evitando los ángulos, y en caso de no ser así, que se obtenga licencia municipal antes de pro-

19 Rupérez Almajano, ob. cit. págs. 272 y ss. Sobre la influencia que tuvieron esas ordenanzas, Rodríguez G. de Ceballos, «Las Ordenanzas de Madrid de D. Teodoro Ardemans y sus ideas sobre la arquitectura”, en Revista de Ideas Estéticas, núm. 114 (1971), págs. 91-110. 
ceder a sacarla a línea, tal como había hecho don Félix de los Arcos. Consideraba asimismo que no se podía privar a la calle de la «igualdad y hermosura» por una ventana, tanto más cuando había otra calle por medio y el cuarto donde se abría tenía además un balcón ${ }^{20}$.

Por el contrario para Simón Gabilán los perjuicios que ocasionaría la nueva construcción eran numerosos y contravenían no sólo uno, sino varios capítulos de las Ordenanzas y el parecer unánime de los arquitectos más autorizados, como trata de demostrar con una acumulación de citas, en un alarde de erudición. Según su parecer, la salida del soportal de once pies con los otros once que se pretendía alargar, dejarían la calle de San Boal en diecisiete pies y medio y la de Zamora en veintisiete y medio ${ }^{21}$, lo que además de dificultar el manejo de los coches y el derecho del marqués de Coquilla a usar la puerta oriental de su casa si así le parecía, incumplía los cuarenta pies de distancia que señalaba el capítulo VII de Ardemans para levantar nueva obra y el cuarenta y dos de las Ordenanzas de Torija donde «se veda todo estorvo y obra en calle que no tenga capacidad para rodar dos coches y gente de a cavallo y a pie todo a un tiempo". Asimismo la elevación en altura de la nueva fábrica ocasionaría una merma del goce de sol y luz y estorbaría la ventilación según el mismo capítulo de Ardemans-, con el consiguiente perjuicio para la salud - «según opinión del príncipe de los arquitectos Marco Vitrubio en el libro primero capítulo quarto, según León Baptista libro primero, capítulos quarto, séptimo y onzeno, Plinio libro onzeno, capítulo diez y ocho, digo cinquenta y ocho", y el sentir de los modernos arquitectos en sus doctrinas, por no tener el palacio más luz y ventilación al mediodía que la ventana expresada. Por otra parte, con la salida de la casa se privaba al vecino de la recreación y la vista de las calles y entrada de la Plaza, de "ver la capilla, altar, misa, y demás funciones que se celebren..., de los encierros de toros..., de procesiones, paseos, y demás que ocurra en dichas calles y plaza de Santo Thomé, como sitios tan principales». A esto se sumaba el perjuicio económico que ya recibía el marqués de Coquilla con la existencia del soportal, pues en la vista ocular había comprobado que las fachadas de las casas de la señora Dopuy,

20 A.CH. V., exp. cit., ff. 11r.-12r. Otero subraya la cita textual de las Ordenanzas en que se apoya.

21 Esta medida difiere de la realizada por el carpintero de la Ciudad para conceder la licencia, donde se señala a la calle de Zamora una anchura de treinta pies entre la casa del marqués de Coquilla y la frontera del conde de Alba, y de treinta y un pies desde la esquina de D. Felix de los Arcos hasta el palacio de Garci Grande que estaba enfrente. A.Ch. V., exp. cit., fol. 14v. y fol. 55r. y $v$. Por lo que respecta a la anchura las Ordenanzas de Ardemans no son tan explícitas, pues si alguna vez habla de los 40 pies, otras aconseja no bajar de los 16 . 


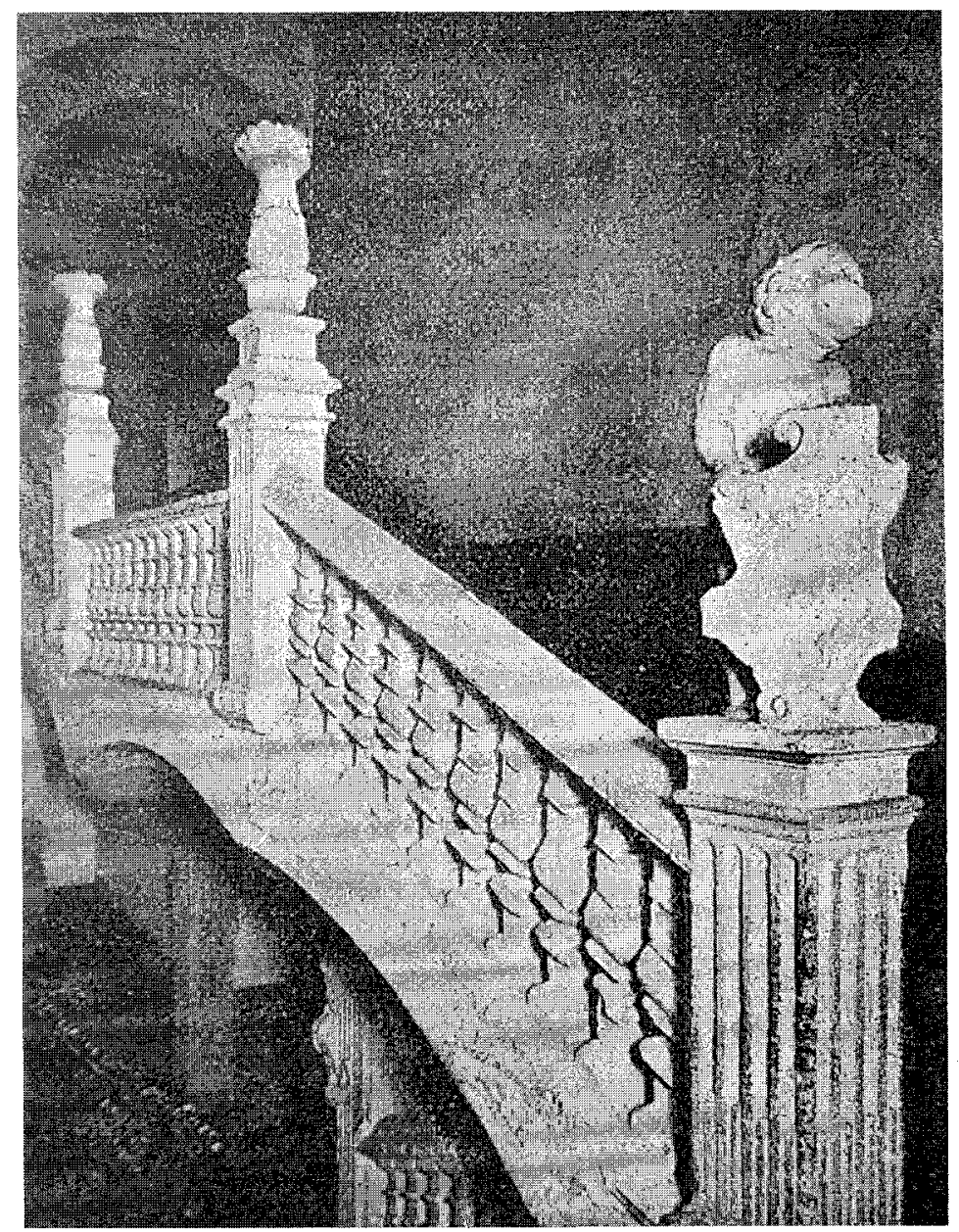

Fig. 4. Escalera del palacio del marqués de Coquilla.

del doctor Cuesta y de D. Félix de los Arcos seguían antiguamente una línea recta, de manera que el palacio del marqués estaba dentro de la plaza de Santo Tomé, aunque en su extremo, pero con la salida del soportal y la obra que se intentaba realizar, había quedado fuera y con ello perdía mucho valor su fábrica y su terreno, «según declaración firmada en Madrid en treinta y uno de diciembre de mil setezientos diez y ocho por Morales, Román, Ruiz, Lara, Caballero, Valenciano, Serrano y Ardemans, maestros arquitectos mayores y alarifes de dicha corte». En opinión de Simón Gabilán el perjuicio se extendía también a otros veci- 
nos, pero para subsanarlo era suficiente la reclamación de uno, de acuerdo con el capítulo noveno de Ardemans y el veintisiete de Torija ${ }^{22}$.

Estas razones son repetidas una y otra vez en informes posteriores, sin más novedad que la incorporación de una alusión «a la magnificencia, antigüedad y especial recomendación de haber sido hospedaje de un monarca (Felipe $\mathrm{V}$ )» ${ }^{23}$, que poseía el palacio, como fundamento sobrado para no tener que padecer ni aguantar las servidumbres de que se le ofendiese en la vista y recreación o le aminorasen las luces, ventilación y sol.

Vistos con objetividad ni los argumentos de uno ni los del otro arquitecto resultan convincentes para probar la mejora urbana y pecan de evidente parcialidad; lo único indiscutible a la luz de su mismo trazado es la pérdida de las antiguas visuales externas de la ventana de llevarse a cabo la nueva construcción ${ }^{24}$.

Ante la discordancia de los informes, era obligado nombrar un tercer maestro, como lo hizo el juez escolástico designando de oficio a don Juan de Sagarvinaga el 25 de junio de 1766. Sin embargo, el marqués de Coquilla, no contento con haber impuesto un tribunal a su medida, trata también de saltarse los trámites ordinarios y, tras dos fallidos intentos de apelación, recusa al maestro designado - «sin ánimo de injuriarle y dejándole en su buena fama y reputación»- y pide la acumulación de su causa con la denuncia que asimismo había interpuesto don Antonio Cuesta, otro de los vecinos. D. Félix de los Arcos ve en este proceder excepcional una maniobra dirigida a entretener y dilatar la obra - con la consiguiente pérdida de materiales y alquileres-y una vulneración de la autoridad judicial, pero su reclamación no encuentra eco alguno en el juez. Este como respuesta ordena proponer de común acuerdo un maestro apto, desinteresado e imparcial, para que haga el oficio de tercero y proceda al nuevo reconocimiento ${ }^{25}$.

El pleito toma entonces un giro nuevo, que deja entrever las estrechas relaciones profesionales existentes entre los maestros de la construcción y

22 A.Ch. V., exp. cit., ff. 13r.-15v. Con la misma erudición y citando a los mismos autores, Simón Gabilán defenderá cuatro años después el derecho del prior de la catedral a levantar la tapia de su corral, para evitar el registro desde la hospedería del colegio de San Bartolomé, aunque con ello quitase luz y aire a esas habitaciones. Instituto Diego Velázquez, ms. 38.

23 Quadrado alude a este hecho pero establece una distinción entonces inexistente entre la casa de los Monroyes señores de Villanueva de la Orbada y los Vázquez Coronado. QuADRADO, J.M ${ }^{a}$, Salamanca, Ávila y Segoria. Salamanca, Ed. Daniel Cortezo, 1884, pág. 198.

${ }^{24}$ A José de Otero le exigieron que ampliase su declaración señalando expresamente la dirección de las visuales del edificio, lo que hizo omitiendo por completo cualquier juicio que habría supuesto dar la razón al contrario. A.CH. V., exp. cit., fol. 15v.-16r.

25 Ibídem, ff. 19r.-23v. 
su diferente cualificación, así como la influencia social de determinados grupos o personajes.

Si bien D. Félix de los Arcos vuelve a acatar la decisión judicial y propone como posible tercero a Francisco Pérez Estrada, suficientemente acreditado por las obras realizadas en la capital y en la provincia, el representante del marqués señala la dificultad de encontrar en toda la ciudad un maestro con la debida preparación, y al mismo tiempo desinteresado, para practicar el reconocimiento decretado. Si creemos este testimonio, parece que aparte de Otero, Gabilán y Sagarvinaga, sólo Jerónimo García de Quiñones - hijo de Andrés García de Quiñones que por estas fechas estaba ausente- y Francisco Pérez Estrada gozaban en Salamanca de la cualificación o el prestigio de «arquitectos», que les permitía ejecutar proyectos, hacer tasaciones o intervenir en este tipo de problemas urbanísticos, pues el resto aunque «corren con el nombre de maestros de obras, no son arquitectos en el arte a que corresponde la materia litigosa». Sin embargo, Jerónimo García de Quiñones era sobrino “o pariente mui cercano» de José Antonio de Otero, maestro favorable a don Félix de los Arcos, y en cuanto a Francisco Pérez Estrada era dependiente del Cabildo de la catedral, en cuya comunidad era prior y canónigo un tío de dicho don Félix.

Existía siempre la posibilidad de recurrir a un maestro foráneo, pero aunque el procurador del marqués sugiere en un principio a don Miguel de la Fuente Velasco, «maestro architectto y de los más conozidos y áviles en el arte, que reside en la ciudad de Zamora, entendiendo en la construcción de quarteles" ${ }^{26}$, casi de inmediato, contra todo derecho, rechaza el nombramiento de tercero ${ }^{27}$ por innecesario. Tras haber conseguido dilatar la causa durante un mes, vuelve a prolongarse con el inusual procedimiento de presentar cada parte en su defensa una información avalada por testigos, todos ellos dedicados a la arquitectura.

El marqués, contradiciendo sus afirmaciones anteriores, además de presentar de nuevo a Simón Gabilán, que ratifica su declaración, recurre al gallego José Español, que como él mismo declara solía trabajar en diferentes obras que ocurrían en las propiedades de aquél, a pesar de que se trató de presentarlo como el único «desinteresado, imparcial e inteligente en el asunto». Posiblemente las mismas circunstancias concurrían en José

\footnotetext{
26 Ibídem, ff. 24r.-26r.

27 La parte de D. Félix de los Arcos defiende esta figura como único medio de que los magistrados puedan dictar una sentencia, al inclinarse la balanza hacia uno de los lados. Ibídem, ff. $34 r .-35 v$.
} 

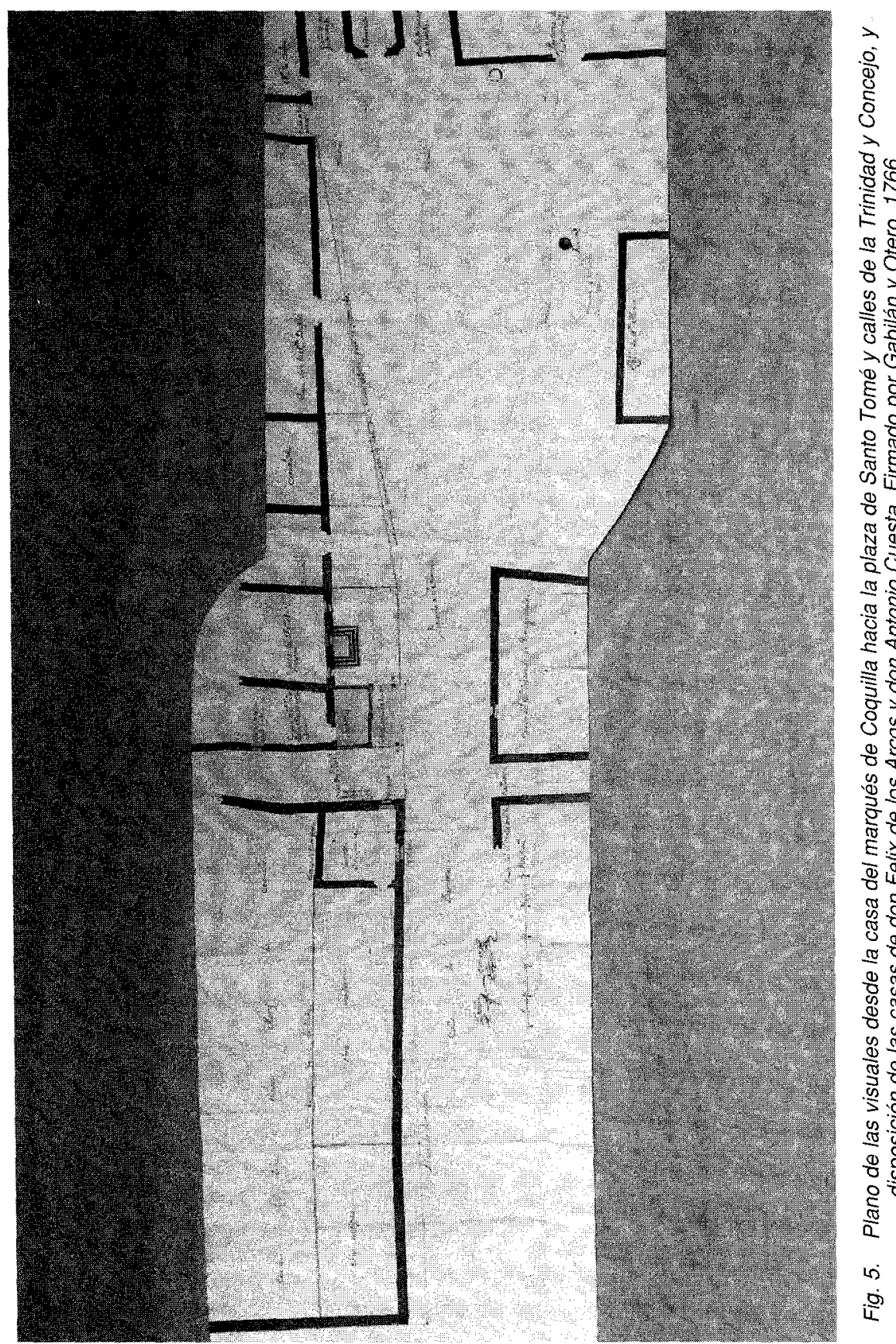
Fernández de la Peña, «maestro arquitecto», Manuel Rodríguez, «maestro de obras particulares» y el gallego Francisco González, que apoyan las razones dadas por Gabilán, si bien algunos reconocen que el alargamiento de la fábrica no impediría el paso de los coches y la existencia inmemorial del viejo soportal.

En defensa de la construcción proyectada por don Félix de los Arcos declaran maestros mucho más acreditados: José de Otero, Juan de Sagarvinaga, Antonio Montero, Juan Alvarez, Nicolás Rodríguez y Francisco Pérez Estrada, calificados todos como «profesores de arquitectura». Con más o menos amplitud y erudición, citan de nuevo el contenido de las Ordenanzas de Torija o Ardemans relativo a la guarda del orden y simetría de los edificios en las calles públicas, si bien, como señala Sagarvinaga, "como estos edificios no se hacen ni proiectan de una vez, siempre se hallan algunas dificultades al tiempo de edificar alguno, y en estos casos, los comisarios de los pueblos acompañados del alarife es costumbre que al tiempo de abrir los cimientos hagan vista ocular, y lo que suele resultar es que quando no se puede llebar línea recta se aproxime todo quanto se pueda a ella, y esto se consigue por lo que corresponde a la casa del marqués de Coquilla sacándose la obra denunciada al igual de su esquina». Frente a esto, la reducción de las luces no sería más que un inconveniente que debe padecer cualquier edificio construido dentro de poblado y carecía de ningún peso al mediar entre los edificios una calle ${ }^{28}$.

Como era de esperar estas informaciones más que resolver la cuestión la complican todavía más. Provocan una serie de acusaciones entre las partes que ilustran aspectos de este mundo laboral pocas veces expuestos de modo tan explícito, aunque pudieran suponerse.

Al parecer existían dentro de los profesionales de la construcción grupos diferenciados no sólo en razćn de su formación, sino también por su vinculación con un determinado arquitecto o promotor, que crea entre ellos unas relaciones laborales de dependencia que limitan su imparcialidad.

Así el marqués de Coquilla señala que Antonio Montero y Francisco Pérez Estrada eran «dependientes» de Juan de Sagarvinaga, que ocupaba el cargo de maestro de la Catedral, pues el primero era obrero menor de esa fábrica y el segundo solía realizar habitualmente los reconocimientos de las obras del Cabildo que se ofrecían fuera de Salamanca. Todos ellos tendrían además interés de agradar al Deán, don Agustín de los

${ }^{28}$ A.CH. V., exp. cit., ff. 37 r. -71 . 
Arcos y Encina, tío carnal de don Félix de los Arcos, lo que éste no puede rebatir suficientemente ${ }^{29}$.

Trata también de desacreditar la licencia obtenida del Ayuntamiento - la principal defensa del denunciado-, basándose en la escasa formación o cualidades del maestro que realizaba habitualmente el reconocimiento y vista ocular que precedian a estas concesiones: un «sujeto que solamente es carpintero de la Ciudad y ningún concepto tiene de arquitectura», que si bien era aceptable para los lugares yermos situados extramuros, "por no seguirse perjuicio alguno a los vecinos inmediatos», de ningún modo se podía tolerar tratándose de calles públicas y con edificios contiguos ${ }^{30}$.

Esta imputación no carecía de fundamento y debía responder a un sentir mucho más amplio. De hecho tuvo un eco inmediato. Resultaría demasiada causalidad que precisamente a partir de este pleito el Ayuntamiento empiece a nombrar un maestro arquitecto que se encargará desde entonces de realizar los informes que antes hacía el carpintero. Inicialmente será Nicolás Rodríguez, vinculado a Sagarvinaga, pero pronto será desbancado por Jerónimo García de Quiñones ${ }^{31}$.

Ahora bien, estas acusaciones del marqués servían también para desacreditar a sus propios testigos. Con excepción de Simón Gabilán, ninguno de los maestros presentados por él eran conocidos en la ciudad como arquitectos, sino exclusivamente como «albañiles o asentadores de obras», cuyo único saber era el que les había granjeado su trabajo, y en este sentido no guardaban parangón con los presentados por la parte contraria, reconocidos "por maestros en el arte y profesión de arquitectura", posiblemente por los conocimientos teóricos que acompañaban su experiencia, aunque fuesen mínimos ${ }^{32}$. Además todos ellos eran «meros dependientes y subordinados a $D$. Simón Gabilán por oficiales de su comando... y seguirían en sus asertos las declaraciones de su maestro y ponderando la falta de concepto por lo notorio que tiene de subordinación en la obra de la Universidad $"{ }^{33}$.

Ibidem, fol. $72 r . y$.

Ibidem, fol. 80v.

31 RupÉrez Almajano, ob. cit., págs. 291 y ss.

32 De hecho el calificativo de maestro «inteligente" suele darse a aquellos maestros que manifestaban un nivel cultural superior al común. Normalmente poseían algunos libros entre sus bienes. Se conocen bien las bibliotecas de Juan de Sagarvinaga y de Gabilán. También consta que Nicolás Rodríguez tenía diez libros de arquitectura. Rupérez ALmAJANO, $M^{\circledR}$ N., «Bibliotecas de artistas salmantinos en el siglo XVIII", en Los Clasicismos en el Arte Español. Actas del X Congreso del CEHA. Madrid, UNED, 1994, págs. 515 y ss. NIETo GonzÁLEZ, J.R., Santa María la Mayor de Ledesma. Salamanca, Librería Cervantes, 1997, pág. 27.

${ }_{33}$ A.CH. V., exp. cit., fol. 85 r. y v. Parece que unos pocos arquitectos dominaban de alguna manera toda la escena arquitectónica salmantina: fundamentalmente los García de Quiñones, 
Trazado visual y limitaciones de la política urbana a finales del Antiguo Régımen...

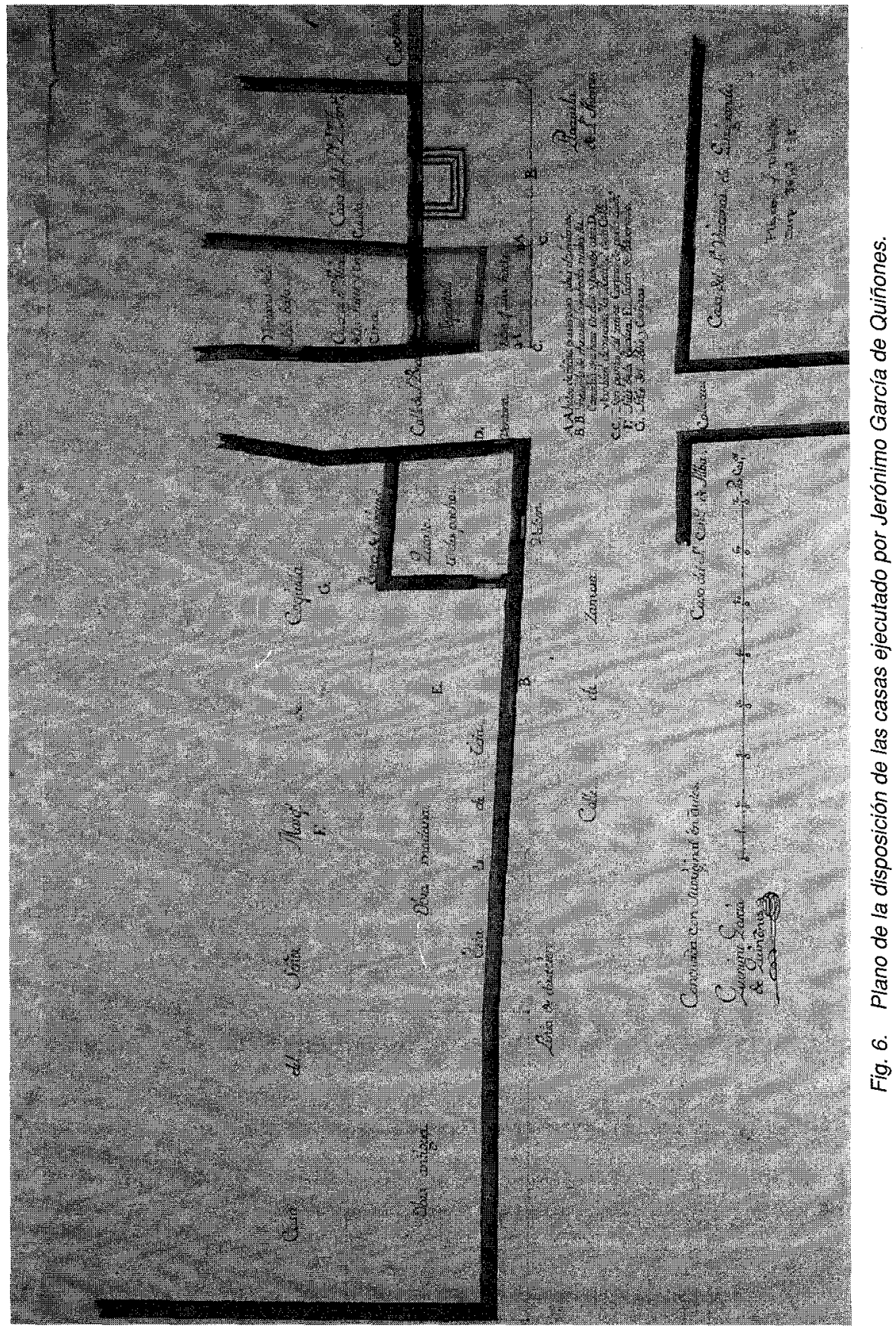


No habría que descartar tampoco un enfrentamiento o enemistad entre Sagarvinaga y Simón Gabilán, pues aunque habían trabajado juntos en alguna ocasión, la competencia que se hacían mutamente es clara, lo que explicaría la recusación del primero por el marqués de Coquilla.

Las acusaciones conducen en el fondo a una oposición entre las principales instituciones de la ciudad: la Universidad por un lado, detrás de su conservador y de su arquitecto, y por el otro el Cabildo y la corporación municipal, detrás de D. Félix de los Arcos, pues no sólo era sobrino del Deán sino también yerno de $\mathrm{D}$. José Miguel Zaonero, regidor perpetuo del Ayuntamiento y Procurador General en el momento del pleito, circunstancia que podía haber pesado en la licencia concedida. De hecho se esgrime como acusación de favoritismo.

Dado el cariz que van tomando las cosas y lo poco que se había avanzado con esta «información» de testigos, el juez escolástico decidió recurrir, para que actuase como maestro tercero, al arquitecto madrileño $D$. Francisco Moradillo, que por esas fechas -finales de agosto de 1766estaba en Salamanca inspeccionando la torre de la catedral. En su informe pretende ser lo más ecuánime posible y aplicar las ordenanzas con más objetividad. Responde a las principales cuestiones planteadas: el tema del soportal, la posibilidad de extender la casa y la rectitud de la calle, proponiendo otra solución para mejorar el trazado del conjunto. En cualquier caso, si algo deja patente es el peso esencial que tiene en todos estos temas la decisión Municipal:

«Siempre que la Ciudad concede lizencia al vecino para labrar, como dueño ya del sitio o terreno puede elevar su fábrica sin que el vecino se lo estorbe, a no ser el demandante combento de religiosas que por obserbar perpetua clausura es razón se le guarde ese decoro y no pribarlas de las luces y ayres, evitando al mismo tiempo todo registro; y así supuesta la ymmemorial posesión en que se alla D. Félix de los Arcos con dicho soportal ... y la lizencia concedida por la Ciudad para su aumento ... a buscar la línea recta con la tirantez de la casa de dicho marqués, parece que no ay razón para privarle de este pribylexio...». Sólo apunta esta posibilidad en el caso de existir un contrato entre las partes, como a veces se daba. La deformidad del soportal era indudable, pero dado que existía desde hace siglos no era ahora el momento de juzgar su conveniencia.

Respecto al orden y uniformidad de las fábricas, que alegaban tanto Gabilán como Otero, reconoce su falta absoluta en la calle de Zamora, 
habiendo incurrido la propia casa del marqués de Coquilla en el defecto de estrecharla y romper la línea que critica a su vecino. En cualquier caso considera que no existe ley alguna que apoye su pretensión, «máxime quando precede tácita y expresa lizencia de la ciudad, a quien corresponde antes de darla ver los incombenientes o utilidades que de ella pueden resultar al común y particular». Sugiere, sin embargo, que tal como estaban las cosas sería conveniente que también se sacase la casa de $D$. Antonio Cuesta siguiendo la línea de la calle Zamora, hasta la misma altura del frontero palacio del vizconde de Garci Grande, para proporcionar mayor regularidad a la plazuela de Santo Tomé, y más «ornato y hermosura» a ésta y a la calle con la apertura de balcones en la planta alta de las nuevas fábricas ${ }^{34}$.

Este informe hacía presagiar una sentencia favorable a D. Félix de los Arcos, pero nada más lejos de la realidad. La resolución deja patente el partidismo del juez escolástico en favor de su aforado. Ignorando la licencia municipal que amparaba a esta parte, el 10 de septiembre de $1766 \mathrm{D}$. Antonio $\mathrm{M}^{\mathrm{a}}$ de Zavala ordenó a D. Félix de los Arcos cerrar los cimientos que tenía abiertos, le prohibió perpetuamente continuar la obra y le condenó a pagar 200 ducados, aunque le permitió conservar el soportar «atendiendo a su inmemorial posesión» ${ }^{35}$.

Aparentemente ei pleito había concluido definitivamente. Sin embargo, después de tres años de silencio, y sin haber mediado apelación al tribunal eclesiástico superior, D. Félix de los Arcos reclamó la sentencia definitiva del juez escolástico ante el Consejo de Castilla alegando fundamentalmente la incompetencia del mismo para conocer una causa «de pura policía», materia reservada exclusivamente a la justicia real ordinaria. Estas cuestiones de policía urbana fueron uno de los frentes que empiezan a erosionar los privilegios existentes. Así, en noviembre de 1769 el Consejo revocó la sentencia, declaró excluido del fuero académico cualquier conservador honorario de la Universidad y ordenó seguir los autos de apelación en la Chancillería de Valladolid.

Reabierto el litigio, de nuevo advertimos el problema que entraña la pluralidad jurisdiccional existente en el Antiguo Régimen para un pronto ejercicio de la justicia. El marqués de Coquilla, que antes había recurrido al fuero universitario como conservador honorario, ahora se niega a admitir la

vinculados familiarmente con los Otero, que habían logrado desplazar a Larra Churriguera de varios de sus encargos - la Plaza Mayor, el fuerte de la Concepción- los Gabilán Tomé y los Sagarvinaga.

${ }_{34}$ A.CH. V., exp. cit., ff. 89-95r.

35 Ibidem, ff. 96r.-97r. 
notificación de emplazamiento de la Chancillería tramitada a través de la Audiencia si no iba cumplimentada por el real tribunal de la Maestranza, de cuyo fuero gozaba como uno de sus caballeros maestrantes. Ante la manifiesta superioridad jurisdiccional de la Chancillería su maniobra no dio resultado, pero logró alargar durante dos años más el proceso. Finalmente el 17 de abril de 1771 el alto tribunal revocó por Real Provisión la sentencia del juez escolástico, absolvió a $\mathrm{D}$. Félix de los Arcos e impuso perpetuo silencio al marqués; el 1 de junio se daba por concluida esta causa ${ }^{36}$.

Sin embargo, esta pequeña variación en el trazado de la calle, que podía haber pasado inadvertida de no ser por la categoría de los vecinos afectados, tuvo todavía ocupada a la Chancillería durante los tres años siguientes. Sancionada la primera denuncia del marqués de Coquilla, todavía quedaba por resolver la que simultáneamente interpuso el doctor Cuesta, propietario de la casa contigua. Sin duda vio la posibilidad de conseguir la misma porción de terreno que su vecino, a tenor del informe dado por Moradillo, pero debía carecer de argumentos medianamente sólidos para justificar su acusación. Después de tres meses sin haberlo hecho, el 10 de noviembre de 1772 el alcalde mayor autorizó a D. Félix de los Arcos para que pudiese seguir la obra hasta su conclusión, dando la fianza demolitoria correspondiente, como así hizo ${ }^{37}$.

Sólo entonces reaccionó D. Antonio Cuesta. A finales de 1772 apeló el auto del alcalde ante la Chancillería, y durante los dos años siguientes se sucedieron de nuevo varios reconocimientos, vistas y declaraciones de arquitectos, con la diferencia de que el Ayuntamiento manifestará ahora un celo desconocido en defensa de sus intereses. Al mismo tiempo D. Antonio Cuesta puso en claro sus intenciones; en diciembre del mismo año 1772 solicitó al Ayuntamiento la cesión del espacio necesario para sacar su casa hasta igualarla con la contigua de D. Félix de los Arcos, con la excusa de proporcionar a la calle un mayor ornato y hermosura.

En esta ocasión los regidores se mostraron más reticentes a satisfacer la petición. D. Julián Rascón, por ejemplo, considera que los perjuicios de esta modificación serían mayores que en el caso anterior, pues no sólo alteraría la línea de la calle de la Trinidad, perdida ya desde la concesión que se hizo a la casa de los Moriroy en el año de "seiscientos y tantos", sino que ocuparía parte de la plazuela de Santo Tomé, «impidiendo a la Ciudad desde sus casas Consistoriales de la Plaza Mayor el ver bajar los toros y excesos que desde allí se pueden corregir y suceden en semejan-

${ }^{36} \quad$ Ibidem, parte primera del expediente.

${ }^{37}$ A. -.P.S., Prot. 5765, ff. 904r. y v. y 959r. y v. 


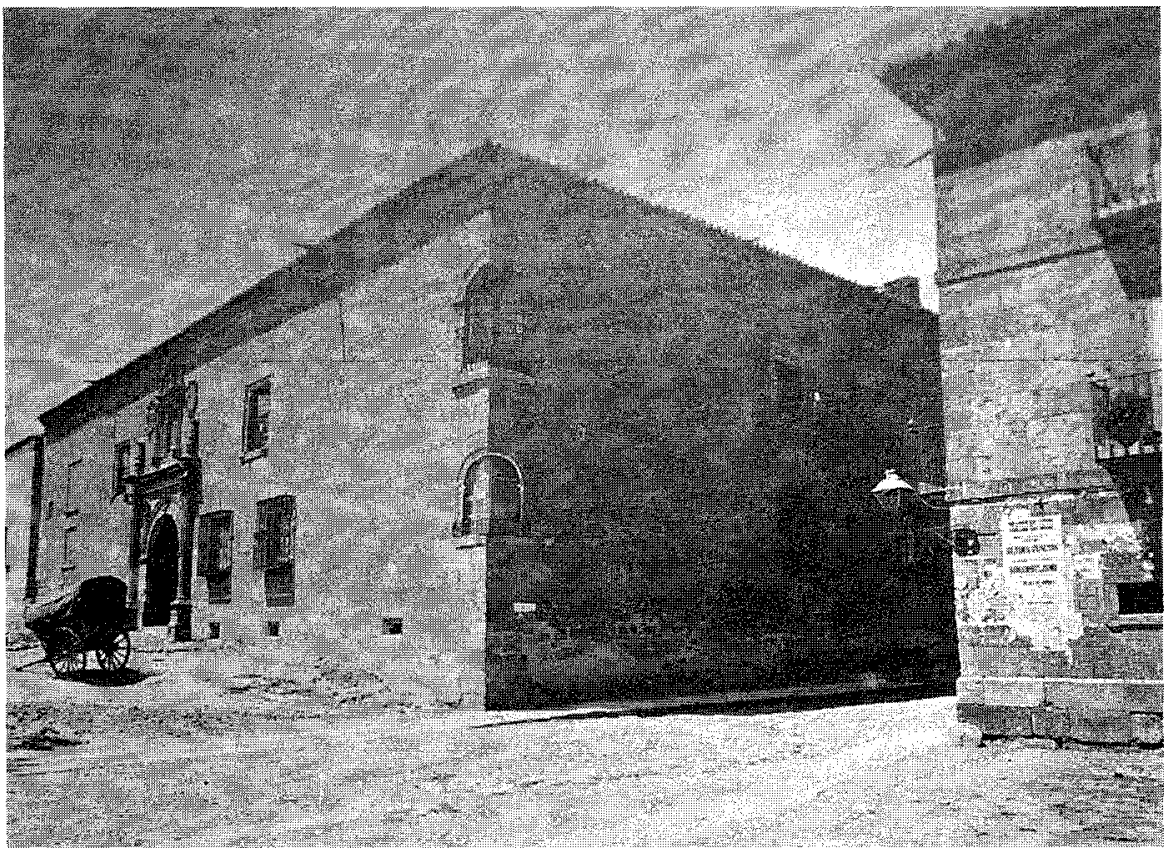

Fig. 7. Plaza de Santo Tomé (actualmente de los Bandos) con el palacio del Vizconde de Garcigrande y a la derecha la ampliación de la casa de don Antonio Cuesta. Segunda mitad del siglo XIX.

tes funciones». Recuerda además que se estaban vulnerando órdenes expresas de S.M., en las que se mandaba a los beneficiados pagar el valor del suelo público enajenado a su favor. Nada de esto se había mencionado con anterioridad ${ }^{38}$.

En el fondo, estamos de nuevo ante el problema de la prioridad del trazado visual frente a la imposición de la línea recta, con la diferencia de que ahora el principal afectado en la reducción de sus visuales será el propio Ayuntamiento, como deja entrever el regidor.

Por otra parte, los trazados lineales admitían interpretaciones tan opuestas, que la objetividad de los informes periciales realizados por los arquitectos, empieza a ponerse en entredicho. Así el Ayuntamiento considera «sospechoso" el informe favorable de Juan de Sagarvinaga apoyando la petición, pues prescindiendo ya de si será cierto o no el "ornato público que pretexta»,

з3 A.M.S., L.C. 1772 , Consistorio ordinario de 11 diciembre de 1772 , ff. 161 r. $-163 \mathrm{v}$. 
reconoce el regidor Nicolás Rascón "que hay maestros para todo» y está enterado que otros tienen declarado lo contrario bajo juramento.

Inducida sin duda por la solicitud y las acusaciones de D. Antonio Cuesta, antes de hacer una nueva concesión de suelo público, la corporación municipal decide comprobar si D. Félix de los Arcos había excedido los límites de la suya y si era verdad que los cimientos abiertos para su casa se adelantaban varios pies con respecto a la casa del marqués de Coquilla, con la que debía guardar la línea recta. Los dos maestros encargados del reconocimiento, Jerónimo García de Quiñones y Simón Gabilán, deberían examinar también cualquier ofensa producida en las visuales de las calles inmediatas, especialmente desde la de la Trinidad - que cerraba la casa de la Ciudad - para que «no se gravasen sus luces y despejo de la calle de Zamora". Al reconocimiento asistieron también varios miembros del Ayuntamiento, D. Félix de los Arcos, D. Antonio Cuesta y otros vecinos.

Los dos maestros emitieron informes separados. Jerónimo García de Quiñones señala que la obra de D. Félix de los Arcos había respetado plenamente la licencia e incluso se había metido un pie hacia el lado de la plazuela de Santo Tomé, pero, para lograr «la hermosura y simetría que debe guardar todo buen gobierno de policía», considera conveniente adelantar también la casa contigua de D. Antonio Cuesta hasta la altura que tenía la parte nueva de la vivienda del marqués de Coquilla. Las dos casas seguirían entonces la línea y simetría con la calle de Zamora y la plazuela de Santo Tomé quedaría perfecta. Bien es verdad que esta mejora impediría la visual desde la calle de la Trinidad hasta la de San Boal, pero ya la obstaculizaba la casa del marqués, resultado de que en «lo antiguo no se guardó en las calles y fábricas de las casas aquella buena uniformidad, simetría y policía que hoy se apetece y está prevenida por Reales Ordenanzas».

Apunta, no obstante, la posibilidad de respetar el trazado visual de la calle Trinidad disponiendo las fachadas en línea oblicua, desde la esquina del palacio del marqués de Coquilla hasta la embocadura de la calle Triperas, y en ese caso el frente de la casa de D. Félix debería retroceder tres pies en un extremo y algo más de cuatro en el otro. El informe emitido por Simón Gabilán coincidía plenamente en este punto, y a él se atuvo la Ciudad a la hora de ceder el terreno a D. Antonio Cuesta y ratificar la licencia concedida a D. Félix de los Arcos, con la condición de que ambos aforasen esos suelos en favor de los Propios ${ }^{39}$.

39 A.M.S., L.C. 1773, Consistorio de 15 de enero, fol. $47 \mathrm{r}$; 27 de enero, ff. $67 \mathrm{r}$.-68r. y consistorio de 12 de febrero, ff. $83 v$.-90r., 17 de febrero, ff. $94 \mathrm{v} .-95 \mathrm{r}$. 
Sin embargo, en lugar de acatar el acuerdo del Ayuntamiento y retirar su fábrica en los términos indicados, D. Félix de los Arcos recurrió la decisión a la Chancillería y contrató diez o doce oficiales y canteros para tener labrada la piedra y preparados los materiales para levantar las paredes de su casa. Esta reacción provocó la inmediata denuncia de nueva obra tanto por parte del Ayuntamiento como, sobre todo, del doctor, que no sabía a qué términos atenerse a la hora de materializar la licencia concedida, especialmente después de que los dos arquitectos volviesen a informar que de ejecutarse las dos casas en línea oblicua o diagonal hacia la esquina de la calle Triperas, siguiendo el trazado visual como habían indicado anteriormente, quedaría en el lado de la calle de San Boal un ángulo muy agudo y en la parte de la casa del doctor Cuesta con la plazuela demasiado obtuso, y por lo mismo con notables imperfecciones ${ }^{40}$.

El nuevo pleito parecía que se iba a acelerar con la muerte de $D$. Félix de los Arcos en septiembre de ese año y la total disposición de su viuda de atenerse a la línea oblicua que marcasen los maestros y comisarios de la Ciudad, pero en diciembre de 1773 todavía se estaba nombrando un tercer perito para decidir la discordia de los designados por las partes, Simón Gabilán y Jerónimo García de Quiñones. El primero, era contrario a la salida de ambas casas, que rompían por completo la antigua línea de la calle Trinidad, el segundo - como ya indicamos- miraba su extensión como una posibilidad de prolongar la calle Zamora y regularizar la plaza. Juan de Sagarvinaga inclinó decididamente la balanza en este último sentido, como había manifestado en su primer informe. Finalmente un auto del alcalde mayor de 11 de agosto de 1774 comunicaba la resolución de la Chancillería favorable a los herederos de D. Félix de los Arcos, de manera que podían proseguir la obra que tenían empezada en su casa de la calle Zamora. Inmediatamente D. Antonio Cuesta recordó al Ayuntamiento la licencia que le había concedido y le suplicó que le permitiese continuar la fábrica de su casa, manifestando su disposición de ejercutarla con las mismas «calidades y circunstancias» que se prescribieron para la inmediata de D. Félix ${ }^{41}$.

A la vista de la resolución del expediente, del que en realidad se había desentendido desde que pasó a la Chancillería, la Ciudad se olvidó de la cuestión de las visuales, y únicamente exigió el pago de un foro anual de 200 maravedís por el suelo concedido y la correspondiente fianza demoli-

40 A.M.S., L.C. 1773, Consistorio 2 de marzo, ff. 110r.-112r.; 6 marzo, ff. 116v.-119v.; 30 de marzo, fol. 155r.; 18 junio, fol. $175 \mathrm{v}$.

${ }_{41}$ A.M.S., L.C. 1773 , Consistorio 1 octubre, ff. 218 r. $-219 r . ; 6$ octubre, ff. $224 v .-225$ v.; L.C. 1774 , Consistorio 5 de marzo, fol. $79 \mathrm{v} . ; 17$ agosto, ff. $166 \mathrm{v} .-167 \mathrm{r}$. 
toria ${ }^{42}$. Este ejemplo deja patente la ausencia de unos objetivos claros en la política urbana desarrollada por el Ayuntamiento y las irregularidades legales que podía llegar a tolerar bien directamente o inhibiéndose del cumplimiento de sus obligaciones.

En 1775 la construcción de las dos casas estaba ya muy avanzada. Acogiéndose a la indicación de Moradillo, no se levantaron sobre arcos como se había proyectado diez años antes ${ }^{43}$, pero en las plantas superiores se dispusieron los consabidos balcones para mayor «lucimiento y hermosura" de la calle y plazuela, según el parecer unánime ${ }^{44}$. Así se aprecia en una fotografía donde aparece una vista parcial de la casa de don Antonio Cuesta, frente al palacio del vizconde de Garci Grande (Fig. 7). Toda la fachada exterior se construyó con sillería limpia; constaba de planta inferior, con pequeños vanos, y dos plantas superiores, divididas por molduras planas, en las que se abrían balcones volados provistos de las típicas bolas de latón en los extremos.

Los planos del siglo XIX reflejan perfectamente la pequeña alteración en el trazado que originan estas construcciones, formando un pequeño saliente en la plaza de Santo Tomé al no estar perfectamente alineadas con la casa del vizconde de Garci Grande.

42 A.M.S., L.C. 1774 , Consistorio 31 de agosto, ff. 176v.-178r. A.H.P.S., Prot. 5212, Escritura de foro perpetuo, 5 de septiembre de 1774, ff. 667r.-670r.; Fianza demolitoria, 3 de septiembre de 1774, ff. $675 \mathrm{r} .-676 \mathrm{v}$.

${ }^{43}$ Moradillo indicó expresamente que la salida de los edificios «no havía de ser portal en lo vajo con columnas ni pilastras, sino zerrado con sus puertas y ventanas en to vajo y balcones en lo alto que diesen ornato y hermosura a dicha calle de Zamora y plazuela de Santo Tomé". En 1772 algunos regidores señalaron en sus votaciones este incumplimiento de lo prometido por parte de D. Félix de los Arcos, pero otros también apuntan que los maestros habían declarado que era «más vistosa la obra según la lleva», o que de este modo tendría uniformidad con todo lo demás fabricado. A.M.S., L.C. 1772 , fol. 162v--163, y L.C. 1773, ff. 67r.-68r. y fol. 90r.

44 El 30 de junio de 1775 D. Antonio Cuesta solicitó el preceptivo visto bueno del Ayuntamiento para poner seis balcones en la casa que estaba construyendo. A.M.S., L.C. 1775, fol. 137r. y v. 